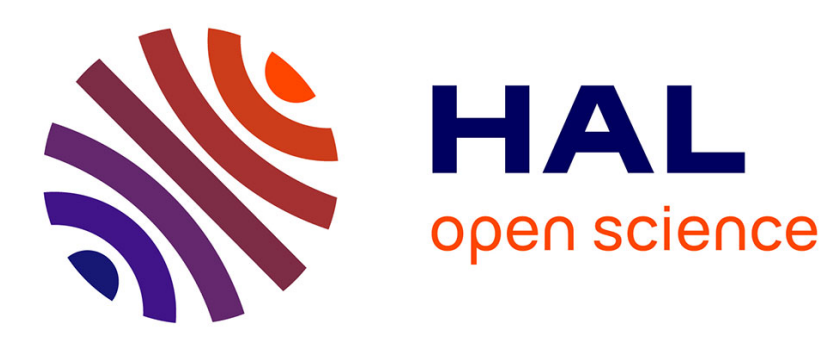

\title{
New transmission lines of negative refractive index based on periodically loaded negative-impedance-converted inductors and capacitors
} X. Hu, S. He

\section{- To cite this version:}

$\mathrm{X}$. Hu, S. He. New transmission lines of negative refractive index based on periodically loaded negativeimpedance-converted inductors and capacitors. European Physical Journal: Applied Physics, 2008, 46 (3), pp.1-5. 10.1051/epjap:2008120 . hal-00480177

\section{HAL Id: hal-00480177 https://hal.science/hal-00480177}

Submitted on 3 May 2010

HAL is a multi-disciplinary open access archive for the deposit and dissemination of scientific research documents, whether they are published or not. The documents may come from teaching and research institutions in France or abroad, or from public or private research centers.
L'archive ouverte pluridisciplinaire HAL, est destinée au dépôt et à la diffusion de documents scientifiques de niveau recherche, publiés ou non, émanant des établissements d'enseignement et de recherche français ou étrangers, des laboratoires publics ou privés. 
Manuscript for Special issue on Metamaterials in the European physical journal AP

Guest-editors: S. Zouhdi and A. Razek

\title{
New Transmission Lines of Negative Refractive Index Based on Periodically Loaded Negative-Impedance-Converted Inductors and Capacitors
}

\author{
Xin $\mathrm{Hu}$ and Sailing $\mathrm{He}^{*}$ \\ Division of Electromagnetic Theory, School of Electrical Engineering, Royal Institute of Technology, S-100 44 \\ Stockholm, Sweden. \\ Centre for Optical and Electromagnetic Research, Zhejiang University, Hangzhou, 310058, China \\ *E-mail: sailing@kth.se, Phone: +46 8-790 8465. Fax: +46 8-205268
}

\begin{abstract}
A new class of negative refractive index (NRI) transmission line is proposed. Differential operational amplifiers are used to form the required lumped elements, i.e., negative-impedance-converted (NIC) inductors and capacitors. In an ideal situation, the equivalent material parameters are non-dispersive, and the phase response of the new NRI transmission line can be complimentary to that of a conventional transmission line over the entire frequency band. As an application example, a broadband 1:4 power divider based on the proposed NRI transmission line is studied.
\end{abstract}

Index Terms-Negative refractive index, transmission line, negative-impedance-converted, non-dispersive

\section{INTRODUCTION}

Negative refractive index (NRI) materials with simultaneous negative permittivity and negative permeability were first investigated by Veselago in 1960s [1] and have gained much attention recently after the first experimental realization [2]. Eleftheriades et al have proposed an inductor-capacitor (LC) (periodically) loaded transmission line (TL) to synthesize an isotropic material exhibiting a negative refractive index [3].

In this paper we propose a new class of transmission lines of negative refractive index by utilizing the operation of negative impedance converters (NICs) [4]. Unlike the existing NRI TL [3], the equivalent material parameters of the proposed NRI TL are non-dispersive (under an ideal condition), and thus can lead to many interesting applications.

\section{THEORY}

\subsection{Distributed Transmission Lines of NRI}

It is well known that dielectric properties like the permittivity and permeability can be modeled with a distributed LC TL. In a TL of generic distributed series impedances and parallel admittances, we can obtain the following equivalent material parameters by comparing telegrapher's equations for the TL with Maxwell's equations for an equivalent material (the field components in the material correspond to the voltages and currents in the TL) [3]

$$
\begin{aligned}
& j \omega \mu=Z \Rightarrow \mu=Z / j \omega \\
& j \omega \varepsilon=Y \Rightarrow \varepsilon=Y / j \omega
\end{aligned}
$$

where $\mu, \varepsilon$ are the permeability and permittivity of the equivalent material, respectively, and $Z, Y$ are the per-unit-length series impedance and parallel admittance of the $\mathrm{TL}$, respectively.

To obtain an equivalent material of positive refractive index (PRI), Eq. (1) implies a TL with $L=\mu(\mathrm{H} / \mathrm{m})$ and $C=\varepsilon(\mathrm{F} / \mathrm{m})$ (in a distributed sense), where $L$ and $C$ are positive per-unit-length series inductance and parallel capacitance of the distributed TL, respectively, shown in Fig.1 (a). To obtain an equivalent material of negative material parameters, the authors of [3] proposed a transmission line of NRI with distributed series capacitance (C') and parallel inductance ( $\left.\mathrm{L}^{\prime}\right)$. However, in such an approach the equivalent material parameters are highly dispersive (though negative) as one has $\mu=-1 / \omega^{2} C^{\prime}$ and $\varepsilon=-1 / \omega^{2} L^{\prime}[3]$.

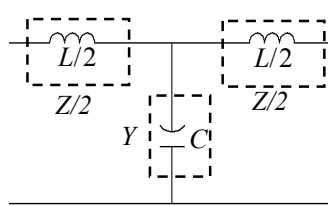

(a)

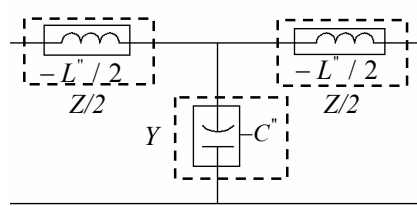

(b)
Fig.1. Unit cells in (a) a distributed PRI TL; (b) a distributed NIC TL

In this paper, we propose another approach by using negative-impedance-converted (NIC) [4] LC TL, as shown in Fig .1(b), that is,

$$
\begin{aligned}
& j \omega \mu=Z=-j \omega L^{\prime \prime} \Rightarrow \mu=-L^{\prime \prime}(H / m) \\
& j \omega \varepsilon=Y=-j \omega C^{\prime \prime} \Rightarrow \varepsilon=-C^{\prime \prime}(F / m)
\end{aligned}
$$

where $\left(-L^{\prime \prime}\right)$ and $\left(-C^{\prime \prime}\right)$ are the negative per-unit-length series inductance and parallel capacitance of the distributed TL, 
respectively. Eq. (2) shows that both the permeability and permittivity of the equivalent material are negative and do not vary with frequency in an ideal case (such a property can be used to design some novel broadband devices; see Section IV). Like an electromagnetic wave in a free space, the corresponding propagation constant of the new NRI TL is proportional to the frequency (instead of $(1 / \omega)$ for the conventional NRI TL [3]), i.e.

$$
\beta=-\sqrt{-Z Y}=-\omega \sqrt{L^{\prime \prime} C^{\prime \prime}}
$$

\subsection{Transmission Line loaded with Lumped NIC-LC}

Here we consider a practical design of a host transmission line $\left(\mathrm{Z}_{0}, k\right)$ periodically loaded with discrete lumped elements, i.e., NIC inductors and capacitors, as shown in Fig. 2, and $\mathrm{p}$ is the period.

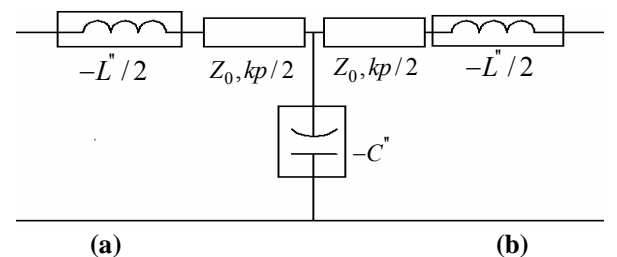

Fig.2. Unit cell in a transmission line loaded with NIC LC

By applying the periodic boundary conditions related to the Bloch-Floquet theorem to the unit cell [5], we obtain the following dispersion relation

$$
\cos \beta p=\cos k p-\frac{\omega^{2} L^{\prime \prime} C^{\prime \prime}}{2} \cos ^{2} \frac{k p}{2}+\left(\frac{\omega L^{\prime \prime}}{Z_{0}}+\frac{\omega C^{\prime \prime}}{Y_{0}}\right) \frac{\sin k p}{2}
$$

It is clear from Eq. (4) that when the period of the structure is infinitesimally small, i.e. $\cos k p=1$, and $\sin k p=0$, the effects of the host transmission line disappear. Furthermore, we can apply Taylor approximation $\cos (\beta p) \approx 1-(\beta p)^{2} / 2$ to Eq. (4) and obtain

$$
\beta p=-\omega \sqrt{L^{\prime \prime} C^{\prime \prime}}
$$

which implies that the phase response of the new transmission line loaded with NIC LC can be complimentary to that of a conventional transmission line over the entire frequency band.

\section{NEGATIVE-IMPEDANCE-CONVERTED L AND C}

Fig. 3 shows an ideal differential operational amplifier with differential input and differential output and its equivalent circuit [6], where

$$
\mathrm{V}_{\text {out }}=\mathrm{V}_{\mathrm{d}} \times \text { Gain }=\left(\mathrm{V}_{+}-\mathrm{V}_{-}\right) \times \text {Gain }
$$

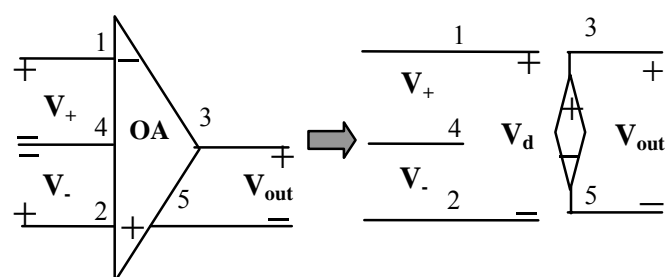

Fig. 3 Differential operational amplifier and its equivalent circuit

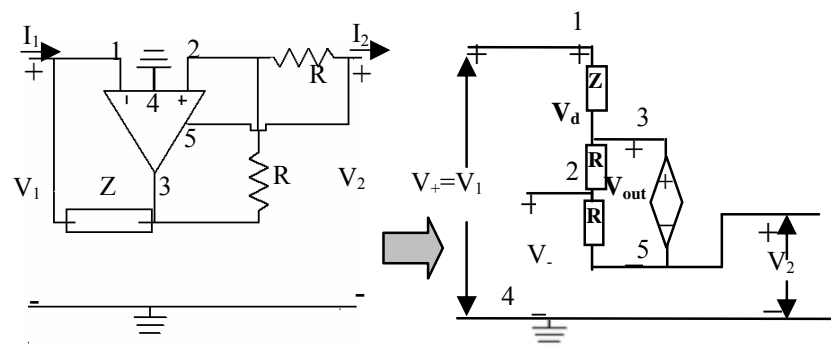

Fig. 4 Negative series impedance converter and its equivalent circuit

By using the differential operational amplifier, we can realize negative series impedance and negative parallel impedance. Fig. 4 shows the negative series impedance converter and its equivalent circuit. From the equivalent circuit, we can obtain the following relations between currents $\left(\mathrm{I}_{1}\right.$ and $\mathrm{I}_{2}$ ) and voltages $\left(\mathrm{V}_{1}\right.$ and $\left.\mathrm{V}_{2}\right)$,

$$
\left\{\begin{array} { l } 
{ I _ { 1 } = I _ { 2 } } \\
{ V _ { \text { out } } = ( V _ { + } - V _ { - } ) \times \text { Gain } } \\
{ V _ { + } = V _ { 1 } = I _ { 1 } Z + V _ { \text { out } } + V _ { 2 } } \\
{ V _ { - } = V _ { \text { out } } / 2 + V _ { 2 } }
\end{array} \Rightarrow \left\{\begin{array}{l}
I_{1}=I_{2} \\
V_{1}=V_{2}+\frac{(2+\text { Gain })}{(2-\text { Gain })} I_{2} Z \\
\stackrel{\text { Gain } \rightarrow \infty}{=} V_{2}+I_{2}(-Z)
\end{array}\right.\right.
$$

Eq. (7) gives the ABCD matrix of the circuit and also shows that the circuit is equivalent to a negative series impedance converter in an ideal case of Gain $\rightarrow \infty$, as shown in Fig. 5(a). Similarly, we can show that negative parallel impedance can be realized by using the circuit shown in Fig. 5(b).
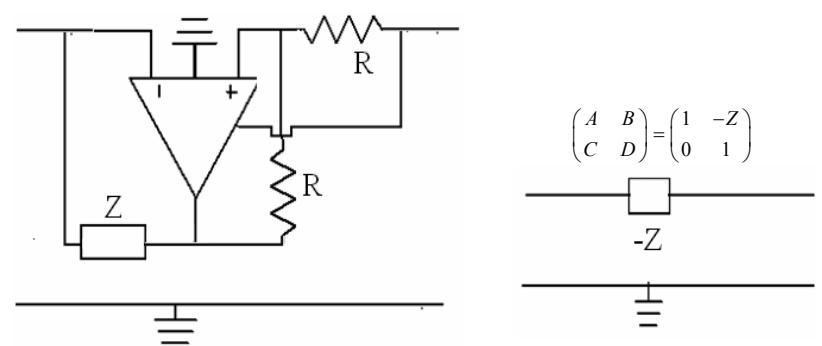

(a) 


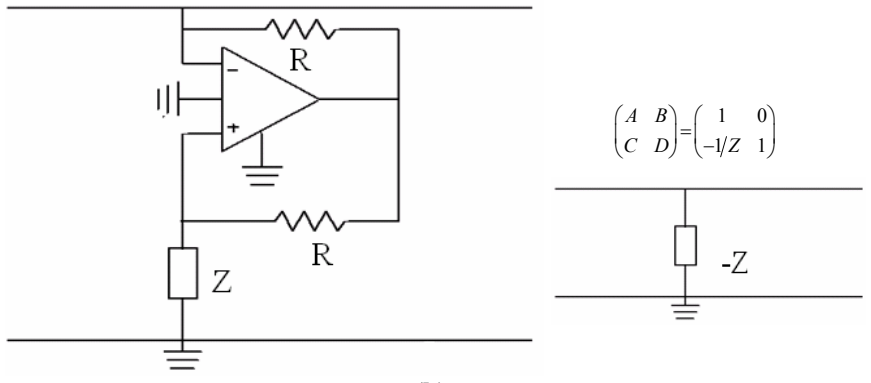

(b)

Fig. 5 Negative impedance converters and the equivalent circuits for (a) series impedance and (b) parallel impedance

If we replace the impedance $\mathrm{Z}$ in Fig. 5(a) or (b) with a capacitor $(\mathrm{C})$, an inductor (L) or a resistance $(\mathrm{R})$, we can obtain the corresponding negative capacitor, negative inductor or negative resistance. By periodically connecting the negative series inductor (replacing $\mathrm{Z}$ in Fig. 5(a) with $\mathrm{L}$ ) and negative parallel capacitor (replacing $Z$ in Fig. 5(b) with $C$ ), we can realize a transmission line loaded with active NIC LC as shown in Fig. 6.

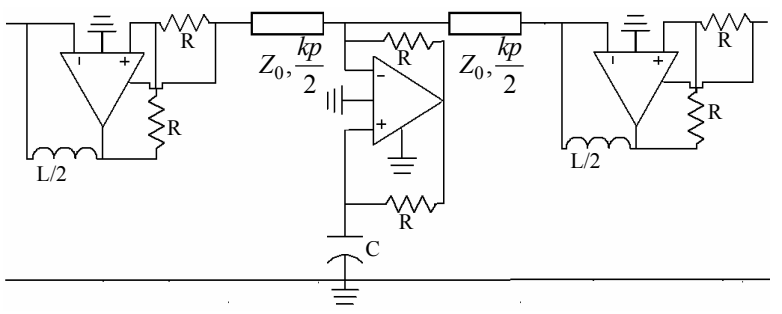

Fig.6. Unit cell of transmission line loaded with NIC LC

\section{A BROADBAND POWER DIVIDER}

The authors of [7] have proposed a broadband 1:4 series power divider using zero-degree transmission lines. Each zero-degree transmission line consists of a conventional NRI structure and a conventional transmission line section (see Fig. 7(a)). As an application example of our NIC TLs, we replace the conventional NRI structure with our NIC TL (see Fig. 7(b)) to obtain a much broader band performance (due to the non-dispersive characteristic of the NIC TL).

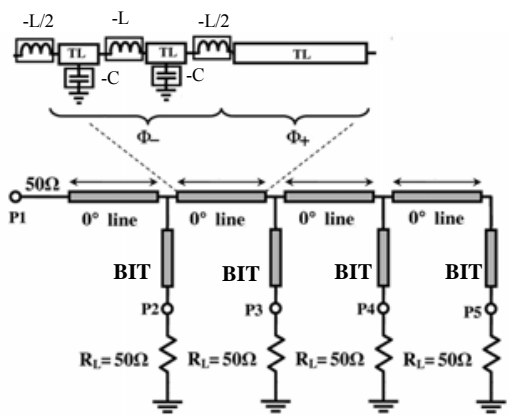

(a)

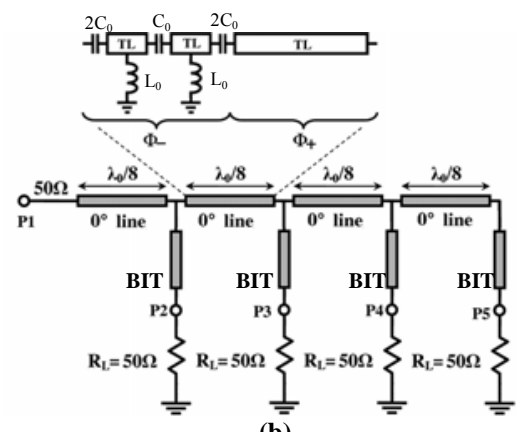

(b)

Fig. 7 Schematic diagram of a series power divider based on (a) conventional NRI TLs and (b) our NIC TLs

The dividers are implemented on a substrate with $\varepsilon_{\mathrm{r}}=2.2$ and height $\mathrm{h}=0.787 \mathrm{~mm}$ at a design frequency $f_{0}=1.92 \mathrm{GHz}$. All our simulations are carried out with the Agilent-ADS microwave simulator using the models of lumped elements and non-ideal microstrip lines. The series divider employs four nonradiating $0^{\circ}$ phase-shifting lines, each of which consists of a conventional TL section [at the end of each phase-shifting line] and two unit cells of TL section (with a characteristic impedance of $70.71 \Omega$ and width $1.39 \mathrm{~mm}$ ) loaded with NRI LC (to cancel the phase of the conventional TL section). To transform from the required load impedance of $200 \Omega$ to test equipment impedance $50 \Omega$, one can use a broadband impedance transformer (BIT) consisting of two quarter-wavelength TLs with parameters [7]: $\mathrm{Z}_{01}=79.06 \Omega$, $\mathrm{W}_{\mathrm{TL} 1}=0.21 \mathrm{~mm}, \mathrm{~d}_{\mathrm{TL} 1}=29.92 \mathrm{~mm}$, and $\mathrm{Z}_{02}=158.11 \Omega, \mathrm{W}_{\mathrm{TL} 2}=$ $1.16 \mathrm{~mm}$, and $\mathrm{d}_{\mathrm{TL} 2}=29.07 \mathrm{~mm}$.

The only difference between the conventional-NRI TL series power divider and our NIC TL series power divider are the loading elements. In the conventional one, capacitors $C_{0}=2.2 \mathrm{pF}$ and inductors $L_{0}=11 \mathrm{nH}$ were employed, while in the proposed one we use NIC-inductors and NIC-capacitors instead and the values of the capacitors and inductors used in the NIC-capacitors and NIC-inductors are $L=1 /\left(2 \pi f_{0}\right)^{2} C_{0}=3.125 \mathrm{nH}$ and $C=1 /\left(2 \pi f_{0}\right)^{2} L_{0}=0.625 \mathrm{pF}$.

Due to the lack of such a high speed $(>2 \mathrm{GHz})$ differential operational amplifier, only the simulated results are given. The results for the two different power dividers are shown in Fig. 8, where we can see there is approximately equal power split to all the four output ports (p2, p3, p4, and p5) at $f_{0}=1.92 \mathrm{GHz}$ for both the conventional and proposed dividers. However, the power delivered to each of the four output ports remains nearly constant over a much larger bandwidth in the proposed divider as compared with the original one. Such a significant improvement is mainly due to the non-dispersive characteristic of our NIC TL (cf. Eq. (2)). 


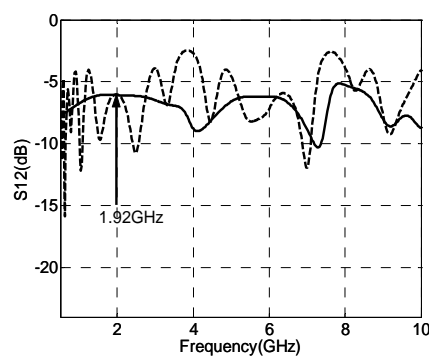

(a)

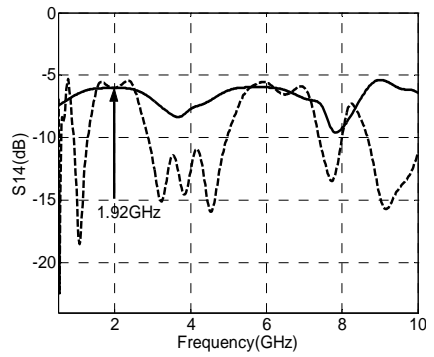

(c)

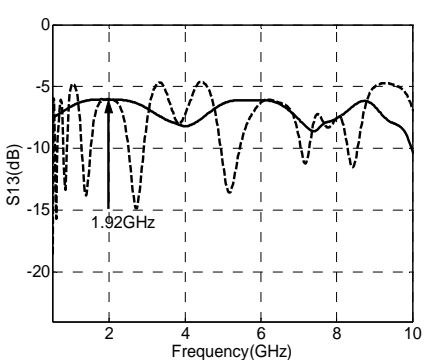

(b)

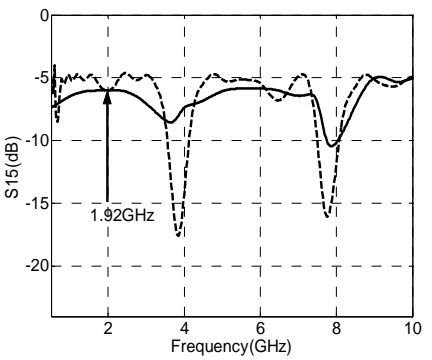

(d)
Fig. 8 Simulated performances at the 4 output ports of the dividers based on the conventional NRI TL (dashed line) and NIC TL (solid line).

(a) S12, (b) S13, (c) S14, and (d) S15.

\section{CONCLUSION}

In this letter we have proposed a new class of negative refractive index (NRI) transmission lines. Differential operational amplifiers have been applied to form the negative-impedance- converted (NIC) inductors and capacitors (lumped elements). Unlike the existing NRI TL, the proposed NRI TL has non-dispersive equivalent material parameters theoretically. The phase response of the new NRI TL is complimentary to that of a conventional transmission line of positive refractive index. As an application example, a broadband 1:4 power divider based on the new NRI transmission line has been studied. The present NIC TL can be extended to a two-dimensional case, and can lead to more interesting applications.

\section{ACKNOWLEDGMENTS}

This work was supported by the National Basic Research Program (973) of China (NO.2004CB719802) and the Swedish Research Council (VR) under Project No. 2006-4048.

\section{REFERENCES}

[1] V. G. Veselago, Sov. Phys. Usp, 10, pp. 509-514(1968)

[2] D. R. Smith, Willie J. Padilla, D. C. Vier, S. C. Nemat-Nasser, and S. Schultz, Phys. Rev. Lett, 84: 4184-4187 (2000)

[3] G. V. Eleftheriades, A. K. Iyer, and P. C. Kremer, IEEE Trans. Microw. Theory Tech, 50, no. 12, pp. 2702-2712 (2002)

[4] P. Horowitz, and W. Hill, The art of electronics, 2nd Ed, Chap. 5 (Cambridge University Press, 1993)

[5] R. E. Collin, Foundations for Microwave Engineering, 2nd Ed, pp. 552-556, 570 (New York: McGraw-Hill, 1992)

[6] B. Carter and T. R. Brown, Handbook of operational amplifier applications, Texas Instruments Application Report, SBOA092A, 2001
[7] M.A.Antoniades, and G. V. Eleftheriades, IEEE Microw. Wireless Compon. Lett. 15, no. 11, pp. 808-810 (2005) 